\section{artelogie}

\section{Artelogie}

Recherche sur les arts, le patrimoine et la littérature de l'Amérique latine

\section{$2 \mid 2012$}

Mexique : espace urbain et résistances artistiques et littéraires face à la « ville générique »

\title{
Carretera 101
}

Jaime Moreno Villarreal

\section{OpenEdition}

1 Journals

\section{Edición electrónica}

URL: https://journals.openedition.org/artelogie/8052

DOI: $10.4000 /$ artelogie.8052

ISSN: 2115-6395

\section{Editor}

Association ESCAL

\section{Referencia electrónica}

Jaime Moreno Villarreal, «Carretera 101», Artelogie [En línea], 2 | 2012, Publicado el 21 enero 2012, consultado el 08 enero 2022. URL: http://journals.openedition.org/artelogie/8052 ; DOI: https:// doi.org/10.4000/artelogie.8052

Este documento fue generado automáticamente el 8 enero 2022.

Association ESCAL 


\title{
Carretera 101
}

\author{
Jaime Moreno Villarreal
}

1 Jaime Moreno Villarreal (México, 1956) fue profesor en la Universidad Nacional Autónoma de México (UNAM) y en la Universidad Autónoma Metropolitana (UAM). Fue Agregado Cultural en la Embajada de México en Francia, de 2007 a 2009. Es miembro del Sistema Nacional de Creadores de Arte de su país.

\section{Carretera 101}

2 El padre de mi abuelo lo mandaba a cazar con la obligación de gastar una sola bala de su carabina. Cazaba para comer. Las municiones eran muy caras para la familia que se dedicaba a curtir pieles salvajes (hacían zapatos, cinturones y avíos para jinetes). Vivían en Cruillas, un pueblo de la sierra tamaulipeca donde sólo habitaban doce familias. Cruillas fue una de las últimas postas en la ruta de diligencias y caravanas que cruzaban la frontera por Reynosa o Matamoros hacia Texas, ruta comercial y también de contrabando. Si mi abuelo fallaba el tiro, y regresaba sin haber cobrado presa, recibía castigo. Me contaba esto cuando íbamos en auto, de cacería, por una brecha, con los rifles asomando por las ventanas. Sólo por probar si mi carabina tenía puesto el seguro, apreté el gatillo y dejé escapar un tiro. Mi abuelo, muy sobresaltado, me reprendió: "Por algo así, yo me habría ganado una buena cueriza."

3 El manejo de armas siempre ha sido común entre la población fronteriza del norte de México, y especialmente en Tamaulipas. En mi adolescencia, visité casas de amigos y conocidos que tenían armarios con cinco o seis pistolas, rifles y escopetas y muchas cajas de munición. La caza en la región era un deporte común, como la pesca. En general el armamento era ilegal, comprado directamente por los particulares en armerías norteamericanas e introducidas a México en las cajuelas de sus autos. Yo pasaba en esa zona los veranos, visitando a mis parientes. Aunque no existía un clima de violencia, se distinguía coloquialmente entre "los buenos" y "los malos", con un candor y una pertinacia que recordaban las películas del oeste. "Los malos" eran gente que le daba mal uso a las armas. Eran criminales, y algunos entre ellos tenían además poder político. Tuve un tío que, al intentar hacerse candidato a presidente municipal de 
Matamoros por el Partido Revolucionario Institucional (PRI), compitió contra uno de "los malos", un sujeto muy conocido que traficaba drogas en avionetas de México a Estados Unidos, y que "debía varias vidas". Fue el traficante quien obtuvo la candidatura, y luego la presidencia municipal por el PRI.

4 Tamaulipas fue colonizado por los españoles muy tardíamente, a fuego y sangre en la segunda mitad del siglo XVIII, unos cincuenta años antes de la guerra de independencia mexicana. Conforme las milicias conquistadoras iban arrancando territorio a los indios nómadas del norte, fueron fundando poblaciones. Cruillas, el pueblo de mi abuelo, data de 1863, y forma parte del municipio de San Fernando. Ahora bien, yo escribo estas líneas por San Fernando, la población donde en 2010 y 2011 se han encontrado fosas comunes con decenas de cadáveres de migrantes y viajeros. Durante toda mi infancia crucé por San Fernando para visitar a mis abuelos: es un punto crucial para mí. Es una pequeña ciudad, una suerte de posta moderna en las rutas hacia la frontera. Por la carretera 101, en viajes de cuatro horas en automóvil desde Ciudad Victoria hacia Matamoros o Reynosa, San Fernando se halla justo a la mitad, población estratégica pero no privilegiada, ciudad de paso de clima extremoso, cercana al mar. Cuando pienso en mis pasos por San Fernando, me vienen a la memoria dos cosas: los curiosos espejismos que se elevan sobre la 101 viniendo de Matamoros-que de niño me sugerían manadas de animales salvajes, torres y una ciudad amurallada-, y el corrido norteño de "Los dos amigos" que un primo y yo, muy buenos amigos, cantábamos por ahí paseando en camioneta, y que narra la historia de dos bandidos que asaltaban pueblos y "trenes grandes y máquinas de vapor".

5 Para mí, San Fernando tiene que ver con el cobro de mi primera pieza. Esa tarde disparé por primera vez una escopeta contra una parvada de palomas de ala blanca. Entre las tres que se desplomaron sobre los surcos, recogí una que aún estaba viva y la llevé al auto, donde mi tío Joel la envolvió en papel periódico. La cacería duró todavía un par de horas y luego enfilamos de regreso por la carretera de San Fernando. En el asiento trasero, yo acariciaba mi paloma de ala blanca que apenas dejaba manchas de sangre en el papel, malherida por un perdigón. Al bajar las yemas de la cabecita al lomo y las alas, sentía sus latidos en mi mano, aterrados bajo la lisura del plumaje gris y blanco tocado por el punto rojo de sangre. En la carretera muy despejada, mientras clavaba mi mirada en sus ojitos de cabeza de alfiler, sentí una enorme necesidad de mantenerla viva, de sanarla con el calor de mis manos y hacerla mi mascota. Poco a poco sus ojos se iban cerrando bajo una membrana delicadísima que subía en su minúscula cuenca ocular. Cuando quedó muerta, sentí decepción de no haberla podido mantenerla viva, pero en verdad no sentí culpa ninguna. Era mi presa. Al día siguiente, salí con mis primos a comprar refrescos, que ahí se llaman "sodas". Al cruzar por un terreno baldío junto a la casa de mis abuelos, uno de nosotros reparó en un periódico ensangrentado que el aire retorcía entre los huizaches. Lo cogimos y extendimos. Era el mismo en que mi tío había envuelto la paloma. Yo no tenía idea de qué había pasado con mi pieza luego de que bajé con ella muerta del coche. Seguramente alguien la arrojó a la basura. No lo comenté con mis primos. El susto de ellos por las manchas de sangre en el papel se redobló cuando leímos la nota roja que contenía el periódico. Traía la foto del cuerpo de un hombre mutilado a machetazos. Le comentamos esto a nuestras mamás, y por varios días fue nuestra anécdota de aventuras. ¡Qué terror! ¡Habíamos encontrado un periódico ensangrentado! ¿Probablemente tenía que ver con aquel crimen ilustrado en 
sus páginas? La verdad era que a mi paloma envuelta, arrojada al baldío, se la habían llevado los gatos.

6 El 29 de julio de 2010, aparecieron los cadáveres de 15 personas en plena carretera, adelante de San Fernando. Los cuerpos habían sido apilados sobre el asfalto para que los vehículos los esquivaran, todos tenían señas de tortura, la cara vendada, las manos atadas y el tiro de gracia. En sus ropas ostentaban la " $Z$ " que indicaba que habrían sido victimados por Los Zetas, ex-brazo armado del Cártel del Golfo, con quienes ahora se disputaban la plaza y las rutas de tráfico de drogas entre Tamaulipas y Estados Unidos. Cuando hablé con mi tía Nora, luego de una balacera que ocurrió a escasas cuadras de su casa, para mi sorpresa volvió a salir el tema de "los buenos y los malos". En esa partición "los buenos" no son la policía federal ni el ejército mexicano, emplazados en la zona, sino que "los de aquí", es decir el Cártel del Golfo, los traficantes locales, mientras que "los malos" son Los Zetas, que llegaron de fuera, originalmente como mercenarios. Hace unos seis años coincidí, en una barbacoa cerca de Ciudad Victoria y San Fernando, con un alto mando de la policía de Reynosa. Al preguntarle casi confianzudamente en qué consistía su trabajo, me respondió: "Agarramos a los malos. Si son buenos, los dejamos ir; pero si son malos, pues les va muy mal.” ¿Estaba diciendo lo que me temo, que la policía estaba del lado de "los buenos"?

7 Ya la gente sabía que Los Zetas tenían un campo de entrenamiento cerca de San Fernando. Cuando comenzaron los grandes decomisos de droga en Tamaulipas, los cárteles se refinanciaron a través de secuestros, extorsiones y robos de vehículos. Muchos incidentes de éstos ocurrían en plena carretera, antes o después de San Fernando, y los vehículos implicados se perdían en las intrincadas brechas que siegan y acotan las tierras de labranza y los cercados. Esas brechas me apasionaban cuando niño, pues en sus rumbos improbables nos perdíamos durante horas viendo cruzar los faisanes, las liebres, los correcaminos, las víboras, y en lo alto los halcones y águilas, hasta llegar a una laguna en donde disparábamos la escopeta sobre parvadas de patos. El relieve de la región es árido, de matorrales y árboles chaparros al pie de la sierra. Sólo en la época de los ciclones del Golfo de México llegan las lluvias. Al volver a casa de mi abuelo, le decía:

- Nos tocó lluvia en San Fernando. - ¿Fue tupida? - Una cortinita. No duró ni tres minutos, muy rara, había una sola nubecita en el cielo.

8 En plena carretera, un paisano fue secuestrado a bordo de su camioneta. El captor lo obligó a internarse por las brechas, y lo liberó al cabo de veinte kilómetros, dejándolo sin zapatos y en calzones. En tal condición el paisano emprendió el camino de vuelta. Horas más tarde, ya muy maltrecho, oyó rumor de motores y vio que su camioneta regresaba por la brecha, escoltada por otro vehículo que dejaba ver armas largas por las ventanas abiertas. Al volante de la escolta, un hombre le mostró al paisano la cabeza degollada del secuestrador: “¿Fue éste el que te asaltó ?" “Sí, señor.” Y le devolvieron su camioneta. Este tipo de historias se contaban en los restaurantes de San Fernando, al principio, cuando todo el mundo se iba de la lengua, pero llegó el momento en que ya fue imposible hablar de cosas así, pues si alguien sazonaba anécdotas y mencionaba nombres, recibía al poco tiempo amenazas telefónicas si no es que, desde otra mesa del restaurante, algún desconocido se levantaba de una vez para exigir que no anduviera alborotando, que se callara.

9 El viernes 17 de junio de 2011, la policía federal presentó ante los medios de comunicación a Edgar Huerta Montiel, jefe de plaza de Los Zetas en San Fernando. En 
agosto de 2010, Huerta Montiel había encabezado el secuestro, en la carretera 101, de dos camiones de carga en cuyo interior viajaban escondidos más de 70 migrantes indocumentados centro y sudamericanos que se dirigían a la frontera. Todos fueron asesinados, excepto uno, un ecuatoriano que logró escapar y denunció el hecho, lo que condujo al descubrimiento de varias fosas clandestinas en las cercanías de San Fernando, de donde se han exhumado más de 200 cuerpos, aunque extraoficialmente Huerta Montiel afirmó que debía haber más de 600 cadáveres enterrados en la zona. El presunto móvil de los asesinatos fue que, según Los Zetas, se trataba de migrantes que habían sido contratados por el Cártel del Golfo para engrosar sus filas. Al propio tiempo, durante varios meses Los Zetas estuvieron secuestrando pasajeros de autobuses foráneos que cubrían las rutas hacia Matamoros y Reynosa, ya fuera para detectar a jóvenes enlistados por el cártel enemigo o para sumarlos por la fuerza a sus propias filas. Al que se opusiera a esta "leva" se le asesinaba. Muchos de los cuerpos encontrados en las fosas de San Fernando presentaron traumatismos cráneoencefálicos, signos de haber sido ultimados a golpes con objetos contundentes. Al principio, se supuso que los asesinos se habrían ahorrado las balas. Se llegó a decir que, para ellos, esas vidas no valían un tiro. Pero se filtró a la prensa que más bien habían sido obligados a matarse entre sí con mazos y martillos: o matas a éste o él te machaca.

El viernes 17 de junio de 2011, la policía federal presentó ante los medios de comunicación a Edgar Huerta Montiel, jefe de plaza de Los Zetas en San Fernando. En agosto de 2010, Huerta Montiel había encabezado el secuestro, en la carretera 101, de dos camiones de carga en cuyo interior viajaban escondidos más de 70 migrantes indocumentados centro y sudamericanos que se dirigían a la frontera. Todos fueron asesinados, excepto uno, un ecuatoriano que logró escapar y denunció el hecho, lo que condujo al descubrimiento de varias fosas clandestinas en las cercanías de San Fernando, de donde se han exhumado más de 200 cuerpos, aunque extraoficialmente Huerta Montiel afirmó que debía haber más de 600 cadáveres enterrados en la zona. El presunto móvil de los asesinatos fue que, según Los Zetas, se trataba de migrantes que habían sido contratados por el Cártel del Golfo para engrosar sus filas. Al propio tiempo, durante varios meses Los Zetas estuvieron secuestrando pasajeros de autobuses foráneos que cubrían las rutas hacia Matamoros y Reynosa, ya fuera para detectar a jóvenes enlistados por el cártel enemigo o para sumarlos por la fuerza a sus propias filas. Al que se opusiera a esta "leva" se le asesinaba. Muchos de los cuerpos encontrados en las fosas de San Fernando presentaron traumatismos cráneo-encefálicos, signos de haber sido ultimados a golpes con objetos contundentes. Al principio, se supuso que los asesinos se habrían ahorrado las balas. Se llegó a decir que, para ellos, esas vidas no valían un tiro. Pero se filtró a la prensa que más bien habían sido obligados a matarse entre sí con mazos y martillos: o matas a éste o él te machaca.

11 Hace unos veinticinco años, internándonos en la Sierra Madre (Municipio de San Fernando) a la búsqueda de un pueblo fantasma - un caserío ocupado por la maleza y sólo marcado por restos de muros y vanos de puertas -, fuimos a dar a un alambique clandestino donde se producía mezcal. El armatoste y su operario parecían extraídos de una fotografía en sepia. Construido al aire libre frente a una cabaña, el alambique se sostenía con patas de fierro viejo y madera nada firmes. Tenía al pie un enorme cazo bullente, negro de tizne, donde se cocinaban las jimas de agave cuyos efluvios subían por la tubería y los serpentines hasta depositar gotas de licor en una vasija de estaño, licor crudo y con impurezas. Me dieron a probar el alcohol tibio en vaso. Aunque sabía 
mal a mezcal, sabía muy bien a mezcal clandestino. ¿Por qué ese intenso placer que experimento en la tierra de mis mayores por lo recóndito e ilegal? Me hubiera gustado preguntárselo a mi abuelo quien, en la época de la prohibición en Estados Unidos, fue cajero en un casino de Nuevo Laredo, Tamaulipas. El propietario del establecimiento era Al Capone.

El contrabando ha sido práctica común de la población civil de la franja fronteriza. No pienso en bandas de criminales sino en las señoras que pasan productos menudos del otro lado para vender en México, desde chicles y golosinas hasta cigarillos, o las familias que compran allá enseres domésticos, sábanas, cobertores eléctricos y, desde luego, automóviles vetustos. Varios de los ultimados o desaparecidos en San Fernando eran ciudadanos del centro y sur de México, que viajaban con dinero en efectivo a comprar automóviles de contrabando. En otros tiempos, un primo mío traficaba autos. Compraba a precios muy bajos en depósitos de Texas donde se venden los autos cerrados, es decir que los compradores no pueden entrar a la cabina del auto, ni encenderlo, ni abrir el cofre o la cajuela, ni asomar la cabeza dentro por una ventana: sólo pueden apreciarlo por fuera y por debajo del chasis, e introducir el índice por el escape para deducir la condición del automóvil. Por lo mismo, viajan hasta el depósito con un acompañante en otro vehículo donde llevan todo lo necesario para hacer talachas y composturas, auto que será su escolta durante el regreso. Conducen la charchina hasta México, donde le darán mantenimiento para revenderlo. Pero, un momento, antes de emprender la ruta de regreso hacia el puente fronterizo, introducen en la cajuela del vehículo una hielera y un asador, pues si el auto se descompone, será ocasión de preparar una carne asada y disfrutarla con cervezas a un lado del camino.

Años atrás, la carretera 101 pasaba por el centro de San Fernando. Los autobuses se detenían frente a restaurantes que eran al mismo tiempo agencias de transporte donde los viajeros se apeaban para comer un bocado. Tiempo después se construyó un libramiento carretero que alivió al poblado del tránsito, y le dio a San Fernando una nueva dignidad, con su plaza cívica grande y su iglesia blanca. Enamorado de una niña, me recuerdo de nuevo hincado en el asiento trasero del automóvil de mi tío Joel, tomando carretera, mirando cómo San Fernando iba quedando atrás, e imaginando cuántos kilómetros sería capaz de andar a pie para regresar a esa niña, kilómetros infinitos que caminaría sin reposo. Hace dos años, cruzando cerca de San Fernando, recordando mi amor de infancia, vi en el descampado un coyote que se sustraía de la vista al pie de un árbol. Ya era peligroso cruzar por la 101. Me habían aconsejado no hacerlo después de las cinco de la tarde. Este es el último coyote suelto que he de ver en mis días, pensé.

Durante los últimos años de su vida, mi tío Joel se opuso decididamente a las corridas de toros. Yo columbraba en su actitud un arrepentimiento por tanto animal inerme cobrado en esas excursiones de caza menor. A diferencia de los matadores de toros, que ponen de veras en juego la vida, nosotros nos la veíamos con criaturas no fieras. Así desde niño, y como jugando, conocí la vileza de las armas. Llevar un arma en la mano puede enviciar y hacer más cobarde al cobarde. Hay quien se atreve o no a disparar por razones éticas, hay quien da la muerte igual que da la vida, en un acto de nobleza. Pero quien toma una vida por miedo, placer, coacción, desprecio o superioridad (y a veces todo esto va junto), comete un acto de indignidad. Aunque la muerte es finalmente necesaria, entre matar y no matar, en el momento de decisión, se funda ya sea una necesidad o una arbitrariedad. Yo lo viví en la primera adolescencia. Al dar la muerte, 
no se supera el dilema. Persiste siempre el "pude no haberlo hecho". De correría con mi tío por las brechas de los labrantíos, se plantó sorpresivamente una liebre grande, a unos veinte metros del automóvil. Para dispararle, me emplacé frente a la trompa del auto. No podía fallar, sería vergonzoso. Disparé una vez. La liebre no se movió, estaba inmovilizada, como empavorecida, yo había errado el tiro. Di unos pasos más adelante. Apunté con esmero. De nuevo fallé el balazo, y la liebre seguía paralizada. Pensé dejarla por la paz, visto estaba que me había vencido en esa caza absurda. Pero había que matarla. Nunca he sanado de ese acto. Me acerqué más, y más. La vi temblar. Qué habría opinado mi abuelo, que gastaba un solo tiro para comer. La maté. Creí por un momento que se me había escapado, pues sólo al recibir el balazo salió de su entumecimiento. Quedó mal encaramada entre matorrales a la vera del camino, la liebre que me había dado tres oportunidades de no matarla. Por coacción, por estupidez, por inseguridad, por inmadurez, por qué. En palabras de uno de los asesinos de San Fernando: "no me quedaba de otra". Pero yo elegí libremente hacerlo.

\section{RESÚMENES}

Ensayo-crónica sobre la relación personal del autor con la ciudad de San Fernando, en el Estado de Tamaulipas, México, en cuyas cercanías han sido encontrados más de 200 cadáveres enterrados en fosas clandestinas, de migrantes y viajeros que fueron ultimados por el cártel de la droga denominado Los Zetas.

\section{ÍNDICE}

Palabras claves: San Fernando, Tamaulipas, Cártel del Golfo, Los Zetas, fosas clandestinas, migrantes, cacería

\section{AUTOR}

\section{JAIME MORENO VILLARREAL}

Escritor, traductor y editor literario, México D.F. 